\title{
Critical factors affecting a successful BIM integrated design solution
}

\author{
Vladimír Nývlt ${ }^{1, *}$, and Radimír Novotný ${ }^{1}$ \\ ${ }^{1}$ The Institute of Technology and Business, in České Budějovice, Okružní 517/10, 37001 České \\ Budějovice, Czech Republic
}

\begin{abstract}
There are arguments, that new technologies in general, which is particularly true for BIM, are an opportunity to change the work routine. On the other hand, recent research shows that successful adoption of BIM depends on allowing the team to adapt new technologies to suit existing workflows. The struggle for power and organizational change occurs when individuals, teams and organizations progressively move through changes to the risks associated with standard procedures, the interests of intellectual property, the financial risks associated with capital investment in both hardware and software, as well as to the investments needed to train and retain technologically advanced employees. So, what should be considered primary if an organization starts implementing BIM? Are non-technical (social) factors more critical than technical or vice versa? And among those who will face all the organizations that are the most critical?
\end{abstract}

\section{Identification of Critical Factors}

Critical factors are certainly the criteria for selecting and identifying BIM software and BIM features, BIM pilot projects, etc. Vytlačil [1] writes that BIM brings an opportunity to change the work routine. In a number of countries, research [2] has already been carried out focusing on identifying these critical factors and proposing their elimination. Also, the financial risks associated with capital investment in both hardware and software, as well as to the investments needed to train and retain technologically advanced employees [3]. Won [4] identified the following list of critical success factors for the BIM (listed in order of importance obtained from extensive research).

-Willing to share information between project participants

-BIM model manager of the entire project through DCO

-Effective cooperation between project participants

- Organizational structure (in companies) supporting BIM

-Permanent investment in development

-Leadership and senior management

-Information Sharing Protocols

-BIM education and training programs

-Technical support for interoperability

\footnotetext{
${ }^{*}$ Corresponding author: nyvlt@mail.vstecb.cz
} 
-Standardized working procedures for BIM

In the above-mentioned survey [4] other success factors have also been identified, but are no longer included in the "critical" category, but they are also important factors to manage BIM and its implementation in organizations and BIM projects itself.

Success factors (uncritical) are:

-Client satisfaction with BIM projects

-Number of BIM experts in the company

-Extensive BIM libraries

-Instruments to support project co-operation

-Shared responsibility between project participants

-Metrics for quantitative evaluation of BIM project effectiveness

-Interest or client request for a BIM project

-Number of subcontractors and partners with experience with BIM projects

-BIM rewards program

If companies choose to implement BIM, it will not be the case for all projects at once, but rather by first attempting to implement implementation in projects where they have sufficient knowledge and confidence to master it. In other words, where to eliminate risks (to be able to work with the most critical success factors).

Sharing knowledge and information, effective collaboration, and sufficient staff and team skills are once again key to creating a "successful BIM knowledge management model" and thus a successful BIM as such.

\section{Impact of Implementation on particular maturity levels}

Implementation of BIM will certainly change the components and relationships between these life cycle phases, and will also change activities and tasks. In addition, these changes will constantly change as gradual transition between BIM levels (BIM maturity levels) occurs. Let's try to deduce hypothetical representations of the impacts from the gradually through BIM maturity levels, which will arise over the life cycle of the building, in terms of the life stages of the building life cycle, the overlap of the phases and the semantic richness of the BIM model. Hypothetical representations are designed as follows:

\subsection{BIM level 0, pre-BIM level}

The construction industry is characterized by competing relationships, where contracts (contractual relationships) promote, in particular, ways of avoiding risks or eliminating risks completely. There is only dependence on $2 \mathrm{D}$ documentation describing $3 \mathrm{D}$ reality. Even in cases where 3D visualization is created, it is disconnected and all refers exclusively to $2 \mathrm{D}$ documentation, including details. Report dimensions, cost estimates, specifications are generally not derived from visualization, nor are they linked to $2 \mathrm{D}$ documentation. These are mostly separate documentation and calculations.

Similarly, no collaborative scenarios are prioritized between each participant when they appear, including the entire workflow, which is linear, fragmented and asynchronous and takes the form of a simple timetable. The Pre-BIM level (Level 0) shows very low investment in IT technology and a significant lack of interoperability.

\subsection{BIM level 1 (basics of object modeling)}

BIM implementation is initiated at this stage by the development of object-oriented, 3D parametric SW tools such as ArchiCAD, Revit, Tekla, ArchiBUS, etc. At this stage, users 
are still creating models focusing on just one discipline, either Design (D) Construction (O) or Use - Operation (O). BIM Modeling Realization Outputs are an architectural project, divesting models, etc. used exclusively to automate the creation and coordination of 2D documentation and 3D visualization. Other outputs are basic data exports (eg door layouts, concrete volumes, cost of elements ...) and a lightweight 3D model that does not have any modifiable parametric attributes.

Scenarios of cooperation at this stage are similar to level 0 . There are no significant data exchanges (computerized) between disciplines. Changes in computer data (drawings, documentation) between users are often indirect, and mutual communication is still nonsynchronous and discontinuous. The process at this BIM level changes only to a small scale, contractual relationships, work with risks, and organizational behavior remain the same as level 0 . However, the semantic nature of object-based models, and their markedly emerging need for detailed design resolution and construction issues, "Through the life cycle phases of the project. Figure 1.

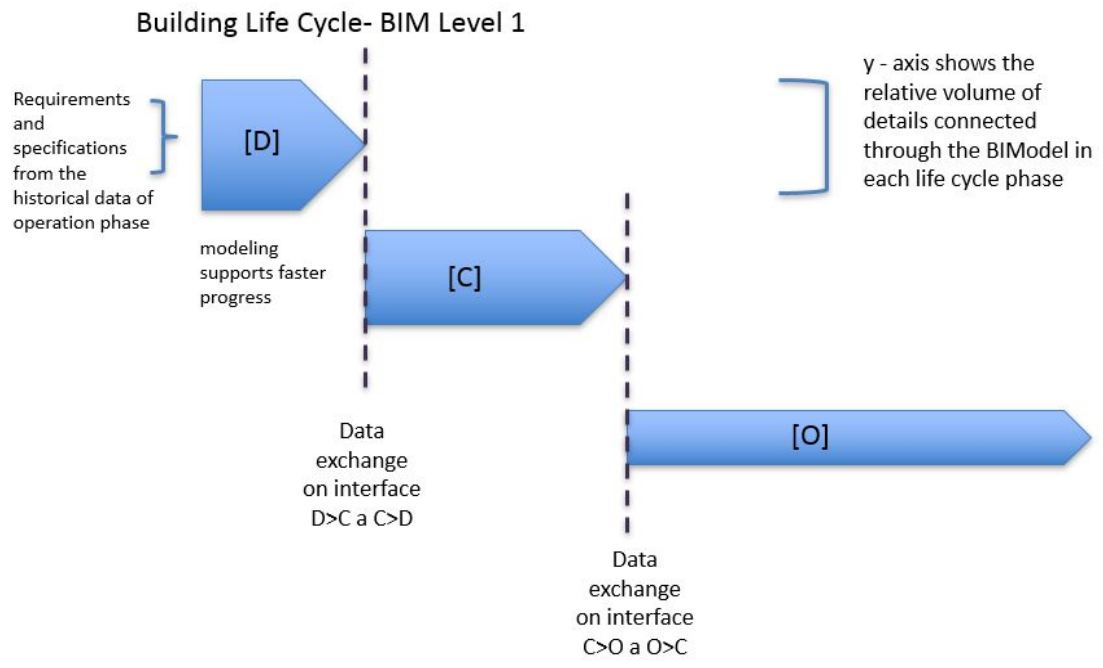

Fig. 1 Building Life Cycle Process at BIM Level 1 - Linear Model (Own Design)

The knowledge model described in this way represents the hypothesis that objectoriented modeling supports process acceleration - although the project is still being phased in - yet "the design and construction activities can partly overlap and thus cost savings" [5]. Here, it is possible to assume that when reaching the full BIM level 1 level, BIM users will acknowledge the potential benefits of inviting other partners in investment construction to BIM modeling techniques and options, and in general BIM environments. This confirmation, followed by the adoption of further actions in this direction, will lead the BIM user to the next stage of maturity of BIM level 2, which is already based on cooperative models.

\subsection{Level 2 BIM - model-based cooperation}

BIM users of individual disciplines (DCO) actively collaborate with each other and within their discipline. This occurs on several technological paths, depending on the BIM SW that is used by the particular user. We will find ways of collaboration based on models that will have the character of the exchange of structured data, further processed directly by other SW applications. They can be both "one family" of applications (eg Revit Architecture and 
Revit Structure, using .RVT data format), but also "from different families" (eg ArchiCAD and Tekla using the IFC data format).

This type of collaboration between SW tools is realized both within one phase of the building life cycle and between two phases. However, there will always be cooperation between two specific phases, eg (DC) - data exchange of architectural and static models (eg calculations and final design of steel structures) between designers and production. Another example is the exchange of model data (DO) - between architectural design and facility management. It is important to note here that $3 \mathrm{D}$ geometric data will be stored in only one of the co-operating models and will allow the exchange of semantic data between two disciplines.

Although communication between BIM users will still be asynchronous, the strict separation of roles, disciplines and phases of the life cycle of a building, as we have seen them in Level 1, will begin to gradually diminish and disappear. As the original document exchange workflow changes to direct data communication between models, it will be necessary to adapt the contractual relationships between individual players in the BIM field. Level 2 BIMs will also change the granularity of modeling that will be implemented at each stage of the building's life cycle by sharing models with greater detail across phases. Fig. 2.

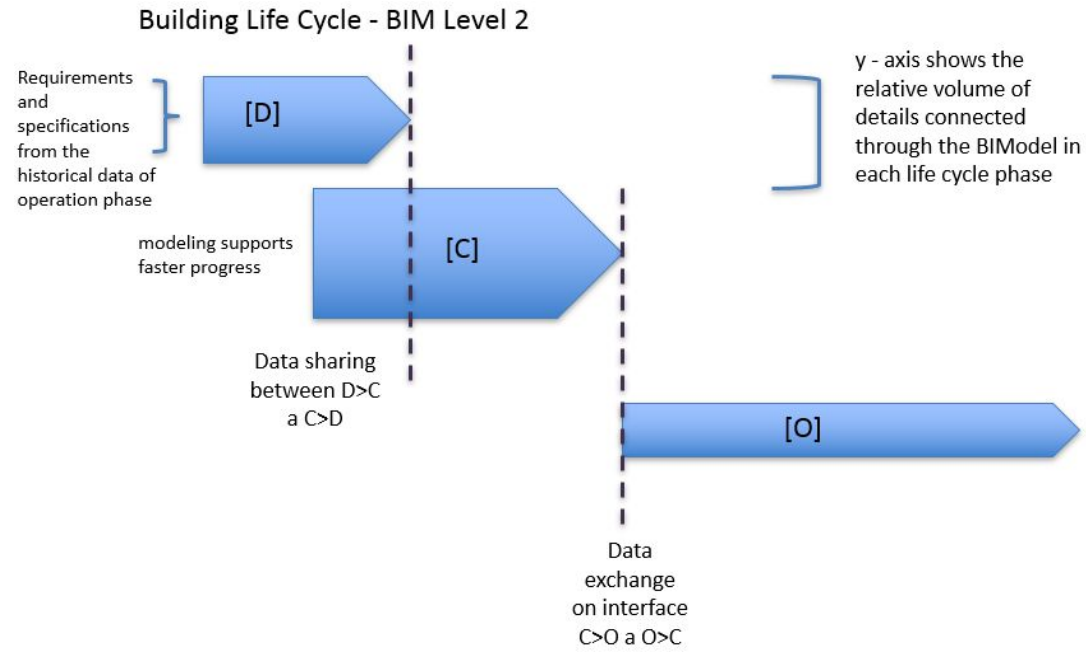

Fig. 2 Building Life Cycle through BIM Level 2, Linear Model (Own Design)

The above-described knowledge model is a hypothesis as to how collaborative BIMbased collaborative models can become a factor in stimulating acceleration and changing the relative intensity of modeling use at each stage of a building's life cycle. It can also be determined that the overlapping between the phases will be more and more determined by construction phase actors in terms of providing additional services related to their own design as part of their offerings as well as design phase actors who will increasingly add information about design, construction and use of their models. Of course, semantic richness throughout the lifecycle will increase, for example, by increasing detail in the construction or building components and will begin to replace the original exclusively architectural features. Data richness of the model will also bring a sharp increase in the total amount of metadata.

\subsection{Level 3 BIM - Network-based integration}


This level will be represented by the creation of semantically rich integrated models that will be created, shared and maintained across all phases of the entire life-cycle of a building. This integration will be achieved through model-server technologies (using proprietary, open and foreign formats) of uniquely integrated and shared databases [6].

Level 3 BIM models become interdisciplinary $\mathrm{nD}$ models [5] which will allow for comprehensive analysis in the initial stages and virtual design including the construction process. The implementation outputs will extend to the semantic properties of the objects and include business intelligence, lean manufacturing principles, environmental policy, and the cost of the entire life cycle of a building. "Collaboration will change into an iterative spiral spinning around extensive, unified, and shared data models" [6].

From a process point of view, synchronous exchange of structured data from both models and documents will support the emergence of overlapping and overlapping of all phases of the project life cycle. Fig. 3 .

The proposed knowledge model is the basis for the hypothesis that integration based on networks will lead to "concurrent implementation" in the sense that "all project activities are integrated and all aspects of design, construction and use are simultaneously planned to maximize the value of real functions while optimizing building construction, building use and security "[7].

Building Life Cycle - BIM Level 3

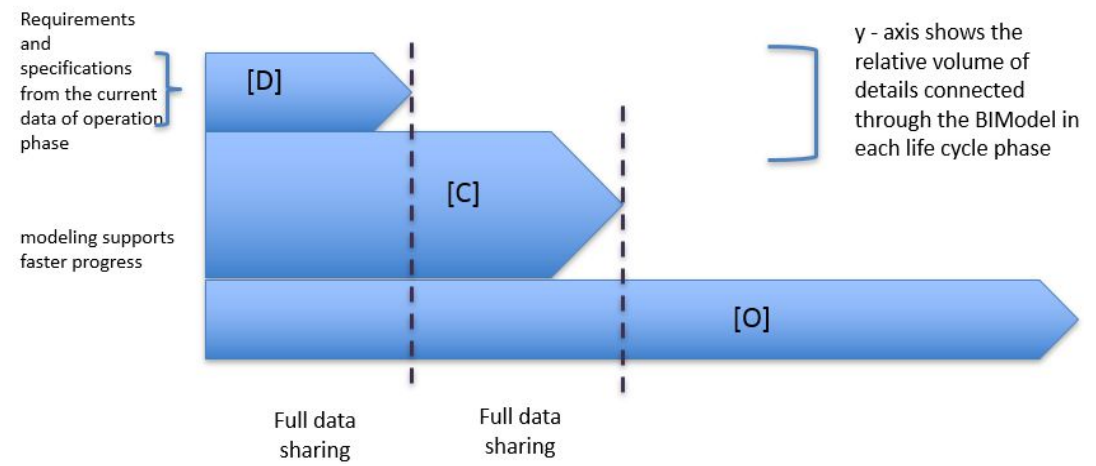

Fig. 3 Project Lifecycle phase according to BIM Level 3 (linear model D-C-O) (Own design)

At BIM level 3, it will be necessary to reassess contractual relationships between stakeholders, risk allocation models and own processes. A prerequisite for all these changes is the achievement of maturity of software and network technologies that will allow the sharing of one interdisciplinary model allowing access for all project participants. Achieving the maturity of all these technologies and user maturity to adopt new processes and principles will lead in the final to the introduction of a comprehensive "life cycle management" or "Integrated Project Delivery".

\subsection{Building Life Cycle Management}

Building Life Cycle Management, it is certainly appropriate to name the long-term vision of BIM development by merging domain technologies, processes and standards. This term is sufficiently generic and potentially comprehensible, certainly more than eg $\mathrm{nD}$ Modeling".

If we call "Building Lifecycle Management", the goal of implementing all BIM components is not to exclude other objectives that have been put under different names over the last two decades. By contrast, BIM is gradually passing through 3 levels as 
described in [5] from pre-BIM level 0 (as a fixed point for the beginning) to the fuzzy BIM defined Level Building Management Lifecycle, how to include all existing BIM visions into one. Some of the aims of the literature are as follows:

Integrated Project Delivery (IPD) is a project delivery approach that integrates people, systems, business structures and work practices into a process that integrates the experience and skills of all participants to optimize project output, increase value for the owner, reducing waste and maximizing performance. All this is going through all phases: design, production of building elements and construction. IPD principles can also be applied to contractual relationships, and IPD teams may include members outside the boundaries of classical participants, ie the owner, architect, and vendor. In all cases, integrated projects are characterized by effective cooperation between the owner, the main designer and the main contractor, from the very beginning of the investment project to the completion of the construction and its approval " [1].

\section{Conclusion}

Integrated Design Solutions "are based on improved collaboration, coordination, communication, decision support, and other workflows, allowing for horizontal, vertical and transient data integration and information management to increase added value across the whole life cycle of BIM process participants buildings. " [1].

The model is an extension of the BIM model by including all project information required at each stage of the property life cycle. $\mathrm{nD}$ modeling "is a parallel use of building information for various analyzes and evaluations ... which will allow participants to try out the building not only in the form of visualization but also in the form of an informative rich interactive system focused on other senses, including acoustics (ambient noise, etc.) nD modeling is a new approach oriented to the integration of existing and non-existent approaches to modeling into a new way of dealing with different project dimensions from the perspective of behavioral prediction and the use of real estate.

Both the volume and complexity of all the changes identified in each BIM level, both in organizational terms, as well as in the design and execution areas, are of the nature of crossing across levels and can not be implemented without incremental evolutionary steps.

\section{References}

1. D. Vytlačil, MATEC Web of Conferences, 146, 01011 (2018)

2. T. Hartmann, A grassroots model of decision support system impliocations by construction project teams. PhD dissertation thesis (Stanford Univ. Palo Alto, USA, 2018)

3. M. Hitka, L. Ližbetinová, S. Lorincová, G. Bartáková, P. Štarchoň, Ch. Li, E. Zaborová, J. Marková, J. Schmidtová, L. Mura, BioResources, 13(2), 2759-2774, (2017)

4. J. Won, C. Lee, C. Dossick, J. Messner, Journal of Construction, Engineering and Management, 139 (2013)

5. K. Prušková, Proceedings of International Multidisiplinary Scientific GeoConference SGEM 2017, 17(62), 821-826 (2017)

6. M. Sůra, MATEC Web of Conferences, 146, 01004 (2018)

7. L. Ližbetinová, S. Lorincová et al, Nase More, 63(3), 170-176 (2016) 